Superalloys 2012: 12 $^{\text {th }}$ International Symposium on Superalloys

\title{
ON THE MECHANISM OF SERRATED GRAIN BOUNDARY FORMATION IN NI-BASED SUPERALLOYS WITH LOW $\gamma^{\prime}$ VOLUME FRACTION
}

\author{
H.U. Hong ${ }^{\dagger}$, I.S. Kim, B.G. Choi, Y.S. Yoo and C.Y. Jo \\ High Temperature Materials Department, Korea Institute of Materials Science \\ 797 Changwondaero, Sungsan-gu, Changwon, Gyeongnam, 641-831, Republic of Korea \\ ${ }^{\dagger}$ Currently at Department of Metallurgy and Advanced Materials Engineering, Changwon National University \\ 20 Changwondaehak-ro, Uichang-gu, Changwon, Gyeongnam, 641-773, Republic of Korea
}

Keywords: Ni-based superalloys, Grain boundary serration, Interfacial energy, Segregation

Abstract

The mechanism of serrated grain boundary (GB) formation and its effect on the intergranular properties in a wrought Ni-based superalloy Alloy 263 containing $\gamma^{\prime}$ volume fraction below $10 \%$ have been studied. It was newly discovered that GBs are considerably serrated in the absence of $\gamma^{\prime}$ phase or $\mathrm{M}_{23} \mathrm{C}_{6}$ at the GBs. The crystallographic analysis revealed that the GBs tend to serrate to have specific segments approaching the $\{111\}$ lowindex plane at a boundary so that interfacial free energy of GB can be decreased, which may be responsible for the driving force of GB serration. The formation of serrated GBs with lower energy leads to a change in the carbide characteristics. The creep resistance can be remarkably improved by serrated GBs, which is associated with a lower rate of cavitation and crack propagation through the modification of carbide characteristics as well as GB configuration. Furthermore, serrated GBs are highly resistant to liquation cracking in simulated weld-heat affected zone due to their lower tendency to be wetted and penetrated by the liquid phase. Electron energy-loss spectroscopy (EELS) studies suggest that serration is triggered by the discontinuous segregation of $\mathrm{C}$ and $\mathrm{Cr}$ atoms at GBs for the purpose of relieving the excessive elastic strain energy. The role of this lattice distortional energy due to the atomic size difference is confirmed on the serration behaviors through binary nickel alloy model systems. The formation of serrated GBs without GB $2^{\text {nd }}$ phase particles begins to occur in Ni-Zr binary system when the content of $\mathrm{Zr}$ with large atomic size is higher than $0.05 \%$, which might lead to a sufficient development of stress exerting a force on GBs.

\section{Introduction}

It is known that the mechanism for the formation of serrated grain boundaries (GBs) in Ni-based superalloys is essentially associated with the precipitation of adjacent coarse $\gamma^{\prime}$ particles at the GBs [16]. Koul and Gessinger [2] reported that the model for GB serration was based on GB primary $\gamma^{\prime}$ movement causing displacement of the local GB segment. In line with this model, the strain energy difference between the matrix side and the boundary side of the $\gamma^{\prime}$ particle-matrix interface provided a driving force for the movement of the primary $\gamma^{\prime}$ particles in the direction of the boundary until this force was balanced by the line tension of the boundary. Additionally, Koul and Thamburaj [6] have claimed that a $\gamma^{\prime}$ solvus temperature should be higher than the solvus temperature of the major GB carbides $\left(\mathrm{M}_{23} \mathrm{C}_{6}\right.$ or $\left.\mathrm{M}_{6} \mathrm{C}\right)$, and $\gamma^{\prime}$ particle size adjacent to GBs should exceed $0.8 \mu \mathrm{m}$ for the development of serrations. Thus, earlier studies on the serrations have been confined to alloys containing $\gamma^{\prime}$ volume fractions in excess of 15 to $20 \%$ since they believed $\gamma^{\prime}$ solvus temperature and size increases with increasing $\gamma^{\prime}$ volume fraction $[2,6]$. Little literature has been found related with the GB serrations and their effects in wrought nickel-based superalloys containing $\gamma^{\prime}$ volume fraction below $15 \%$.

Meanwhile, the present authors have recently found that the GB serration occurs in the absence of $\gamma^{\prime}$ phase or $\mathrm{M}_{23} \mathrm{C}_{6}$ in a wrought Ni-based superalloy Alloy 263 which has only $10 \%$ volume fraction of $\gamma^{\prime}[7,8]$. This new finding appears to challenge established models. Therefore, the present paper is focused on the mechanism of serrated GB formation, and aims to develop a better understanding of the role of serrated GBs on the resistances to intergranular degradation.

\section{Experimental}

The starting material was a commercially available Alloy 263 with composition (wt.\%) Ni-20Co-20Cr-6Mo-0.06C-0.4Al-2.1Ti containing $<30 \mathrm{ppm}$ boron present as a trace solute impurity. The as-received sample which was solution-treated from a manufacturer had a mean grain size of $65 \mu \mathrm{m}$ with a small fraction of MC. Zhao et al. [9] confirmed for Alloy 263 the $\gamma^{\prime}$ solvus temperature $\left(900^{\circ} \mathrm{C}\right)$ is lower than the $\mathrm{M}_{23} \mathrm{C}_{6}$ solvus $\left(919^{\circ} \mathrm{C}\right)$ through both detail microstructural observations and thermodynamic calculations. Besides, the alloy has about $10 \% \gamma^{\prime}$ volume fraction with an average precipitate size of around $20 \mathrm{~nm}$ $[7,9]$. Hence, it appears that no serration is expected in Alloy 263 according to recent models [1-6] proposed by a series of phenomenological experiences in nickel-based superalloys.

Samples of about $7 \times 10 \times 10 \mathrm{~mm}$ in size were cut from a piece of the alloy for heat treatment tests. The samples were solutionannealed $\left(1150^{\circ} \mathrm{C} / 30\right.$ minutes) followed by water-quenching (WQ). Aging treatment $\left(800^{\circ} \mathrm{C} / 8\right.$ hours) was then conducted. This heat treatment, characterized by a two step process, is conventionally used for this alloy. A special heat treatment was designed by the authors $[7,8,10]$ to produce serrated GBs with a proportion of over $80 \%$. The samples were solution-annealed at $1150^{\circ} \mathrm{C}$ for 30 minutes and slow-cooled to $800^{\circ} \mathrm{C}$ at a cooling rate of $5 \sim 10^{\circ} \mathrm{C} / \mathrm{min}$, subsequently aged for 8 hours at the same temperature.

Scanning electron microscopy (SEM) was performed on a JEOL JSM-5800 microscope with a tungsten filament operating at 20 $\mathrm{keV}$. Transmission electron microscope (TEM) characterization was performed on a field emission type JEOL JEM-2100F operating at $200 \mathrm{keV}$. Electron energy-loss spectroscopy (EELS) signals were collected with $0.5 \mathrm{eV} /$ channel dispersion using a JEOL JEM-2100F equipped with a post-column Gatan image filter system (Gatan Inc., Warrendale, Pa). The EELS-based energy filtered TEM (EFTEM) technique allows maps of the carbon and chromium along the GBs. The serrated GB plane normal was obtained from the cross product of at least two beam 
directions which are parallel to the GB plane. In this situation with the narrowest boundary area, the GB could be seen as a line. This method has been exclusively used for other alloy systems [11-13]. The segregation of boron at GBs in each sample was detected using secondary ion mass spectrometry (SIMS). The SIMS analysis was performed in a Cameca Nano-SIMS 50 instrument using $16 \mathrm{keV} \mathrm{Cs}+$ as primary ions. SIMS ion images showing the distribution of boron in each sample were acquired by mass separating (mass resolution $>20,000$ ) and imaging ${ }^{11} \mathrm{~B}^{16} \mathrm{O}^{-}$ molecular ions with atomic mass 27 .

A cylindrical specimen of $6 \mathrm{~mm}$ gauge diameter and $25 \mathrm{~mm}$ gauge length was employed for both tensile and creep tests. Tensile tests were carried out in air at $22^{\circ} \mathrm{C}$ and $780^{\circ} \mathrm{C}$ with strain rate of $8 \times 10^{-5} \mathrm{sec}^{-1}$. Constant load creep tests were conducted in the temperature/stress conditions of $760^{\circ} \mathrm{C} / 295 \mathrm{MPa}$ and $815^{\circ} \mathrm{C}$ $/ 180 \mathrm{MPa}$. Creep strain was continuously monitored using capacitive transducers connected to extensometers clamped to the humps at the end of specimen gauge section. The measurement of creep strain was initiated prior to loading of the creep specimens.

Weld heat-affected-zone (HAZ) microstructures were simulated by a thermal cycle simulation system of Formastor FII (Fuji Electronic Co., Japan) equipped with a high frequency induction coil specified by $400 \mathrm{kHz}$ frequency $/ 1.5 \mathrm{~kW}$ output. Cylindrical specimens of $3 \mathrm{~mm}$ diameter and $10 \mathrm{~mm}$ length were rapidly heated to $900 \sim 1300^{\circ} \mathrm{C}$ at a rate of $111^{\circ} \mathrm{C} / \mathrm{s}$ and then held for 1 second at each of the temperatures followed by helium gas quenching. The susceptibility of the alloy to HAZ cracking was evaluated by Gleeble hot ductility testing in a Gleeble 3500 using a cylindrical specimen of $6 \mathrm{~mm}$ diameter and $110 \mathrm{~mm}$ length. The hot ductility testing was conducted in an argon atmosphere using a heating rate of $111^{\circ} \mathrm{C} / \mathrm{s}$, hold time at test temperature for $0.5 \mathrm{~s}$, cooling rate of $19^{\circ} \mathrm{C} / \mathrm{s}$ (for on-cooling tests), and a stroke rate of $25 \mathrm{~mm} / \mathrm{s}$.

In order to investigate the influence of alloying elements on the onset of GB serration, Ni-based binary model alloys (Ni-xZr, Ni$0.6 \mathrm{C}$ ) were prepared with about $100 \mu \mathrm{m}$ grain size. Button type of ingots with $40 \mathrm{~mm}$ diameter and $15 \mathrm{~mm}$ height were prepared by the vacuum arc remelting (VAR) method. Every ingot was machined to get cylindrical specimens with $8 \mathrm{~mm}$ diameter and 12 $\mathrm{mm}$ height. The specimens were hot-compressed at $1050^{\circ} \mathrm{C}$ with the true strain of 0.9. Then, the hot-compressed specimens were solutionized at $1150^{\circ} \mathrm{C}$ for $5 \sim 500 \mathrm{~min}$ in order to get the same recrystallized grain size of around $100 \mu \mathrm{m}$. Finally, by using these solutionized specimens, the special heat treatment was carried out to investigate whether or not the GB serration occurred.

\section{Results and Discussion}

\section{The occurrence of GB serration and its effects on microstructure}

As previously reported by the present authors [7,8,13], the controlled cool from 1150 to $800^{\circ} \mathrm{C}$ has led successfully to GB serration. This new finding appears to challenge established models. Figure 1 shows comparisons of GB morphology and carbide characteristics after the formation of serrated GBs. The conventional heat-treated specimen contains fine blocky carbide particles distributed densely at straight GBs, as shown in Figures $1 \mathrm{a}$ and $1 \mathrm{~b}$. The strings of GB carbides were identified as $\mathrm{M}_{23} \mathrm{C}_{6}$ with a very small fraction of MC which is negligible for the comparison of carbide characteristics.
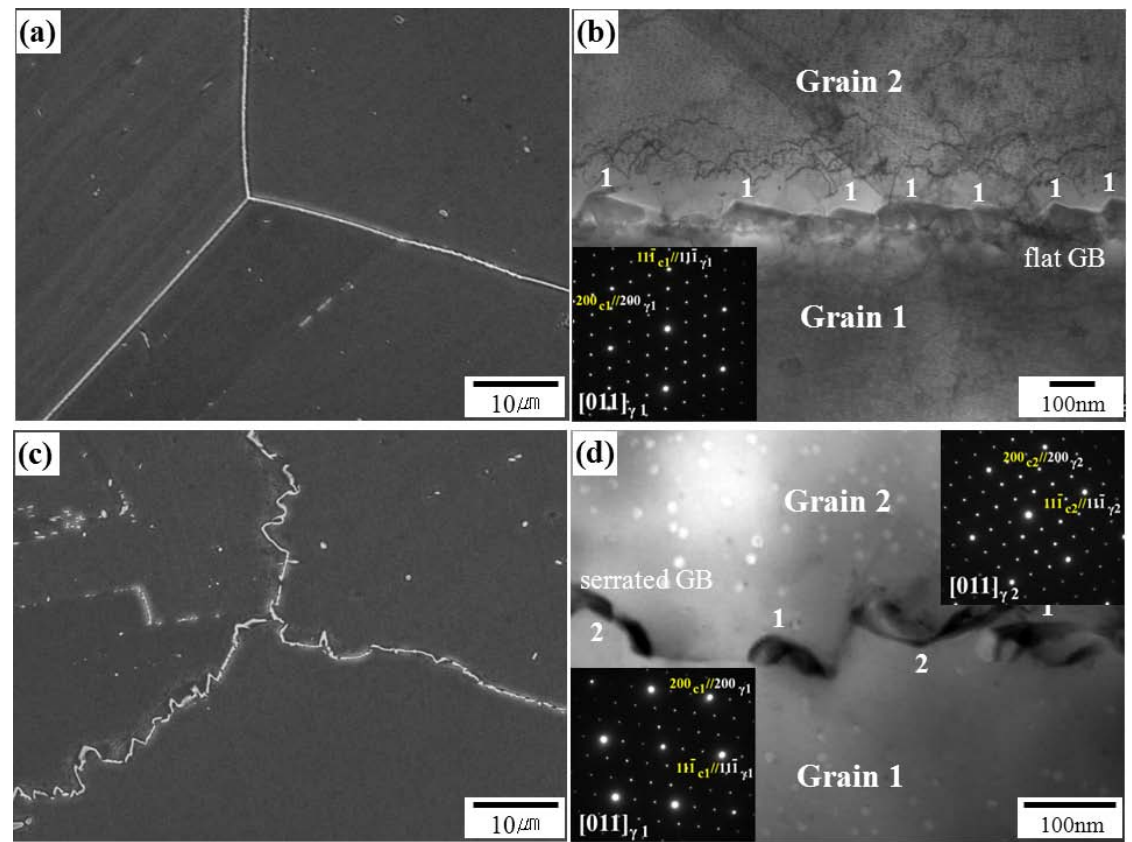

Figure 1. Comparisons of GB morphology and GB carbide characteristics depending on the occurrence of GB serration: The standard heattreated specimen contains (a) flat GBs, (b) fine granular GB carbides with a consistent coherency array, and the special heat-treated specimen contains (c) serrated GBs, (d) planar GB carbides with an alternate coherency array. Note that each digit in (b) and (d) indicates the grain sharing coherency with each carbide formed at the GB. Figures 1a and 1c are SEM images and Figures 1b and 1d TEM images. 

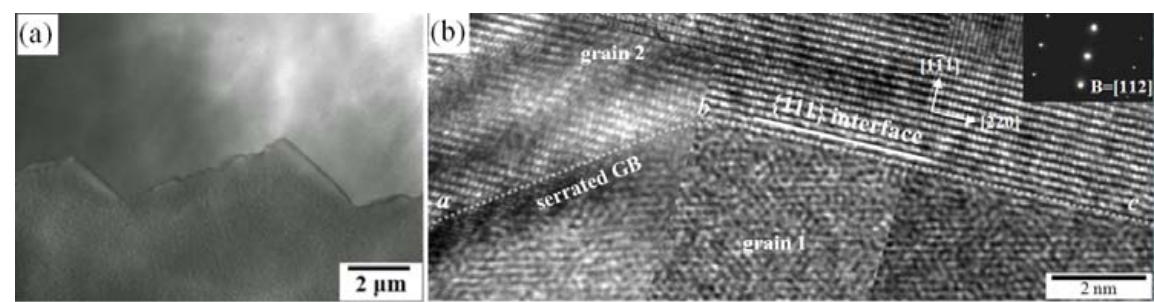

Figure 2. A typical serrated GB at the early stage of slow cooling process: (a) TEM micrograph and (b) high resolution STEM image when beam direction was aligned to [112] of grain 2 .

All the blocky carbides on the flat GB tend to share the coherent interface with grain 1 for which one of the $\{111\}$ planes makes the smallest angle with the GB plane [14], as shown in Figure 1b. The fine spherical $\gamma^{\prime}$ particles are distributed uniformly in the $\gamma$ matrix. Image analysis on seven TEM images taken from different regions showed that $\gamma^{\prime}$ particles had an average size of $16 \mathrm{~nm}$, and a volume fraction of around $10 \%$. As shown in Figures 1c and 1d, the serrated GBs were formed in the special heat-treated specimen. With the introduction of GB serration, the carbide morphology is changed from granular to planar, and the linear precipitation density of carbides at GBs is remarkably decreased from $4.7 \times 10^{4}$ $/ \mathrm{cm}$ to $4.3 \times 10^{3} / \mathrm{cm}$. Additionally, the preference of carbide precipitation on the basis of shared coherency has changed from a uniform distribution to a selective precipitation on alternate serrations (Figure 1d). In the serrated sample, the fine spherical $\gamma^{\prime}$ particles distribute uniformly in $\gamma$ matrix with a volume fraction of around $10 \%$, similar to those in the conventional heat-treated specimen. However, the average size of $\gamma^{\prime}$ particles became larger, from $16 \mathrm{~nm}$ to $18 \mathrm{~nm}$, as a result of the slow cooling.

Based on the sequential observation of the serration evolution $[7,13]$, it was found that the initial flat GB became wavy and formed the serrated configuration during the early stage of the slow cooling process (when a specimen was cooled from $1150^{\circ} \mathrm{C}$ to $1000^{\circ} \mathrm{C}$ at $10^{\circ} \mathrm{C} / \mathrm{min}$ ). Figure 2 shows the typical appearance of serrated GBs prior to $\mathrm{M}_{23} \mathrm{C}_{6}$ precipitation [8]. Neither carbide nor $\gamma^{\prime}$ particle could be observed on the serrated GB. Therefore, it is suggested that the GB serration occurs in the absence of $\mathrm{M}_{23} \mathrm{C}_{6}$ or $\gamma^{\prime}$ particle.

In order to identify the driving force responsible for the formation of serrated GBs, a crystallographic analysis on the serrated GB was conducted. The serrated GB can be divided into at least two segments, i.e. ab, bc and cd segments, as shown in Figure 3.

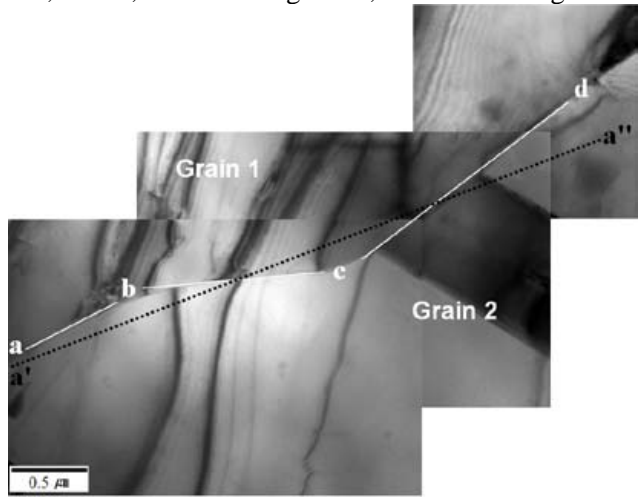

Figure 3. TEM micrograph showing the serrated GB. Note that ab, bc and cd lines correspond to wavy-type segments, and a'a" to initial flat GB.
Table I. Crystallographic features of grains 1 and 2, depending on the type of GBs in Figure 3

\begin{tabular}{ccccc}
\hline & GB plane in & GB plane in & & \multicolumn{2}{c}{$\begin{array}{c}\text { Angle between }\{111\} \\
\text { plane and each GB plane }\end{array}$} \\
\cline { 5 - 5 } & grain 1 & grain 2 & Grain 1 & Grain 2 \\
\hline $\begin{array}{c}\text { ab } \\
\text { wavy- } \\
\text { type } \\
\text { segment }\end{array}$ & $(0.97,0.18,-0.15)$ & $(-1,1,-1)$ & $\mathbf{4 1 . 2}^{\circ}$ & $\mathbf{0}^{\circ}$ \\
\hline $\begin{array}{c}\text { bc } \\
\text { wavy- } \\
\text { type } \\
\text { segment }\end{array}$ & $(0.69,-0.63,0.37)$ & $(0.29,0.30,-0.91)$ & $\mathbf{1 3 . 8}^{\circ}$ & $\mathbf{3 0 . 1}^{\circ}$ \\
\hline $\begin{array}{c}\text { cd } \\
\text { wavy- } \\
\text { type } \\
\text { segment }\end{array}$ & $(0.68,0.36,-0.64)$ & $(-0.95,0.19,-0.23)$ & $\mathbf{1 4 . 3}^{\circ}$ & $\mathbf{3 7 . 4}^{\circ}$ \\
\hline $\begin{array}{c}\text { a’a” } \\
\text { initial } \\
\text { flat }\end{array}$ & $(0.85,-0.48,0.22)$ & $(0.04,0.38,-0.93)$ & $\mathbf{2 6 . 3}^{\circ}$ & $\mathbf{4 3 . 4}^{\circ}$ \\
\hline
\end{tabular}

It is assumed that the serrated GB in Figure 3 is formerly flat in shape, i.e. a'a" dotted line. The crystallographic features of grains 1 and 2 in Figure 3 are summarized in Table I. It is found that during GB serration, the GBs tend to move to have specific segments approaching to $\{111\}$ low-index plane at a boundary. It should be also noted in Figure $2 \mathrm{~b}$ that after serration, the grain 2 plane terminates on a $\{111\}$ low-index plane to make the "bc" wavy boundary segment. This implies that the serration process can change the nature of GBs from "random" to "special" since special GBs are defined with a lower energy as those terminated by low-index boundary planes such as $\{111\}$ [15]. Thus, the fundamental driving force for the GB serration stems in part from lowering interfacial free energy of GB per unit area.

In order to investigate the influence of the GB serration on boron enrichment, the fraction of GBs that are boron-enriched in the standard heat-treated sample (referred to as 'unserrated sample', hereinafter) and the special heat-treated sample (referred to as 'serrated sample', hereinafter) was compared. It is believed that the melting point depressing element boron could be primarily involved in liquation since its segregation at GBs significantly lowers the melting point of the boundaries $[16,17]$. As shown in Figure 4, it is evident that the serrated GBs exhibit a lower concentration of boron than the unserrated GBs: the serrated sample contains $41.6 \%$ GBs resistant to boron enrichment as compared to $14.6 \%$ in the unserrated sample if GBs are classified as resistant to boron enrichment if intensity is lower than $10^{3}$ counts per second in the Nano-SIMS boron images. Furthermore, as published before [8], comparison of the line scan profile across each GB revealed that the serrated GB shows smaller width of boron-enriched area as well as lower intensity. Therefore, this result indicates that the serrated GBs would show a higher resistance to GB liquation cracking during welding. 

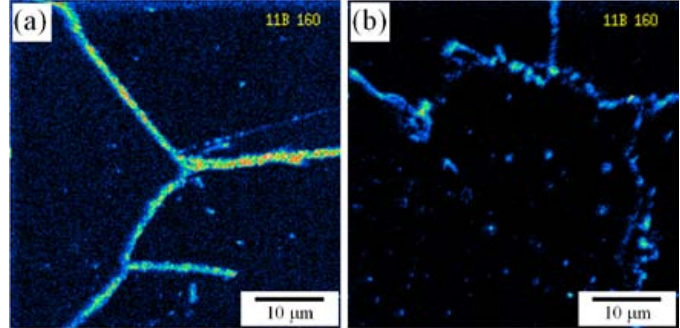

Figure 4. Nano-SIMS boron images of (a) unserrated GB and (b) serrated GB.

The heat treatment for GB serration, associated with slow cooling, should be more susceptible to large non-equilibrium boron segregation than conventional heat treatment. Nevertheless, the serrated GBs are highly resistant to boron enrichment compared with the unserrated GBs. This large difference in boron enrichment at GBs between the unserrated and serrated samples can be attributed to the different GB characters. For nonequilibrium segregation, the important factor is the ability of the boundary to act as a vacancy sink. Special GBs are not available while random GBs (loosely packed GB interfaces) can operate as highly efficient vacancy sinks. Thus, the serrated GBs being considered as special boundaries may be resistant to nonequilibrium boron segregation. For equilibrium segregation (during isothermal aging treatment), significant variations in boron concentrations of each GB are related with GB character [18,19]. According to McLean [19], the equilibrium concentration of segregating atoms at GBs is largely dependent on the binding energy between the segregating atom and GB. Hence, the interfacial energy of GB would determine the degree of boron segregation during aging treatment since the unserrated and serrated samples show the same boron content and have negligible difference in grain size. Similarly, the serrated GBs with lower interfacial energy may be resistant to equilibrium boron segregation while boron atoms are more likely to segregate into the unserrated GBs.

Effect of GB serration on creep property
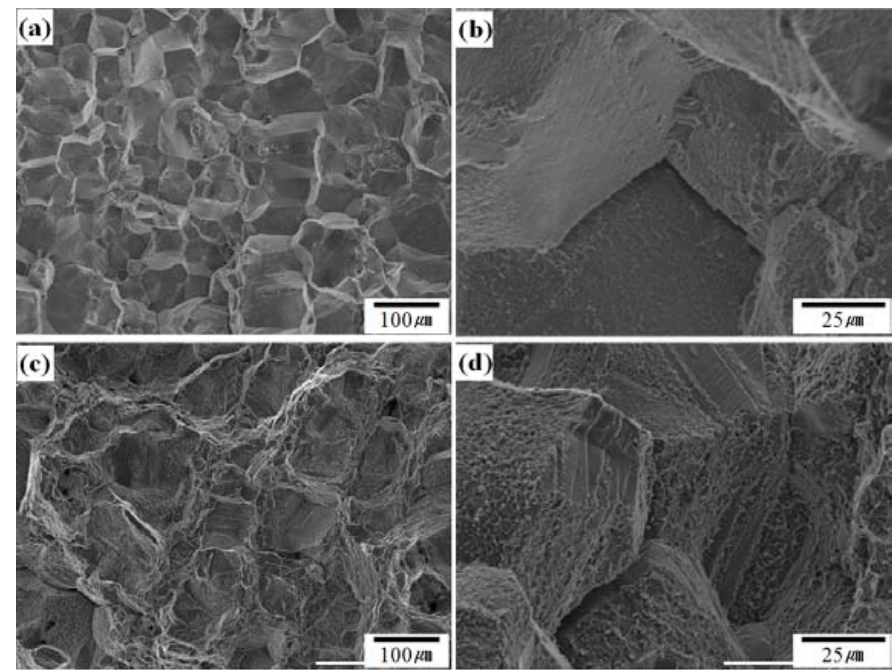

Figure 5. Secondary electron images showing a comparison of the fractured surfaces between the two creep samples tested at $760^{\circ} \mathrm{C} / 295 \mathrm{MPa}$ : (a), (b) show the unserrated sample and (c), (d) show the serrated sample.
The present authors reported previously the improvement of creep resistance resulting from serrated GBs [7]. An optimum condition, where the GB serration occurred appropriately without any significant change in grain size and $\gamma^{\prime}$ size, was determined (a combination of $5 \mathrm{~min}$ solution treatment time and $10^{\circ} \mathrm{C} / \mathrm{min}$ cooling rate). The influence of heat treatment parameters on GB serration and microstructures is dealt with elsewhere [7]. Tensile test results indicate that the introduction of the serrated GB morphology, coupled with the modification of carbide characteristics, has little influence on the tensile properties except for a slight decrease in the strength for the serrated samples. Both yield and tensile strengths showed a reduction of 20 30 MPa.

Table II shows a comparison of creep resistances between the two samples in the temperature/stress conditions of $760^{\circ} \mathrm{C} / 295 \mathrm{MPa}$ and $815^{\circ} \mathrm{C} / 180 \mathrm{MPa}$. The creep lives observed in the serrated sample are about $40 \%$ longer than those of the unserrated sample for the both conditions. The total creep strain can also be increased by the GB serration.

Table II. Comparison of creep resistances between the two samples

\begin{tabular}{ccccc}
\hline \multirow{2}{*}{$\begin{array}{c}\text { Creep } \\
\text { condition }\end{array}$} & \multicolumn{2}{c}{ Rupture time (hr) } & \multicolumn{2}{c}{ Total creep elongation (\%) } \\
\cline { 2 - 5 } & Unserrated & Serrated & Unserrated & Serrated \\
\hline $\begin{array}{c}760^{\circ} \mathrm{C} \\
/ 295 \mathrm{MPa}\end{array}$ & 129 & 178 & 5.8 & 10.8 \\
\hline $\begin{array}{c}815^{\circ} \mathrm{C} \\
/ 180 \mathrm{MPa}\end{array}$ & 181 & 252 & 16.5 & 19.7 \\
\hline
\end{tabular}

Examination of the fractured surfaces after creep testing shows a clear difference, as shown in Figure 5. Noticeable deformation is found on the GB facets containing several steps in the serrated sample while sharp GB facets indicating little deformation near GBs is observed in the unserrated sample. Furthermore, the zigzag array of cavity formation in the serrated sample makes it more difficult for cavities to link up to form an intergranular crack propagation path [7]. 
Consequently, the serrated sample is highly resistant to intergranular damage because of a lower rate of cavitation and crack propagation along GB during creep. This result is understood in light of the modified GB carbides by serration. In the case of serrated sample, the dispersed nature of planar carbides show a higher resistance to cavity formation because of their lower interfacial energy. Also, the zigzag array of incoherent interfaces of the planar carbides leads to the lower crack propagation rate because of its retardation of cavity interlink. Therefore, the improvement of creep resistance in the serrated sample is attributed to not only GB configuration but also the modification of carbides through GB serration.

\section{Effect of GB serration on HAZ liquation cracking behavior}

The weldability of heat-resistant nickel-based superalloys has been of great interest because of the wide use of welding to fabricate and repair service-damaged hot section components for advanced power plants. These alloys, especially those containing a substantial amount of $\mathrm{Al}$ and $\mathrm{Ti}$ ( $>6 \mathrm{wt}$ pct), are highly susceptible to microfissuring predominantly in the HAZ during welding and postweld heat treatment (PWHT). As HAZ liquation microfissuring is an intergranular phenomenon that occurs at elevated temperatures due to GB liquation and grain coarsening, the present authors initiated a study to examine the effect of GB serration on the properties of the HAZ with a consideration of this serration as a potential of a damage-tolerant microstructure. As previously stated, it can be expected that the serrated GBs show a higher resistance to GB liquation cracking during welding process due to their higher resistance to boron enrichment.

The authors found GB serration as a viable means of improving the resistance of nickel-based superalloys to HAZ liquation cracking [8]. $\mathrm{HAZ}$ microstructures simulated at $1180^{\circ} \mathrm{C}$ were observed, an example of which is shown in Figure 6. Liquated GBs are more prominent in the unserrated specimen than serrated one. The liquated segments are observed apart from each other at the GBs, and GB carbides remain occasionally in the serrated specimen. If the liquated GB fraction is defined as the ratio of sum of liquated GB length to total length of GB investigated, the serrated specimen shows $77.5 \%$ whereas the unserrated one shows 93.9\% (based on examination of 150 200 GBs).

As previously discussed, random straight GBs are inherently of higher energy than the serrated GBs considered as "special boundaries". In addition to the difference in boron enrichment, this difference in GB character could be responsible for differences in the wetting of GBs from a liquid film. The distribution of intergranular liquid could be considered along with a GB wetting relationship proposed by Smith [20]:

where $\theta$ is the wetting angle, $\gamma_{g b}$ is the GB energy, and $\gamma_{s l}$ is the solid-liquid interface energy. It is evident from Eq. (1) that for a given solid-liquid interfacial energy, the higher the GB energy, the higher is the tendency for the GB to be wetted and penetrated by the liquid phase [21]. Thus, it can be suggested that the higher resistance of the serrated GB to liquation is most likely to be related to its lower GB energy, causing them less boron enrichment and lower wettability as compared to the random straight GBs. These combined effects of the serrated GB would make it more difficult to cause HAZ liquation cracking.

Gleeble hot ductility test for both the unserrated and the serrated samples has been carried out in order to assess quantitatively the susceptibility to HAZ liquation cracking. The test is based on the premise that the deformation behavior of a material, as evaluated by its hot ductility, reflects its capability to accommodate tensile stresses and resist cracking during the welding thermal cycle [21]. The test results indicate that the serrated sample shows a lower susceptibility to liquation cracking than the unserrated one: the GB serration leads to about $15^{\circ} \mathrm{C}$ decrease in the brittle temperature range (BTR) where HAZ liquation cracking is most likely to occur.
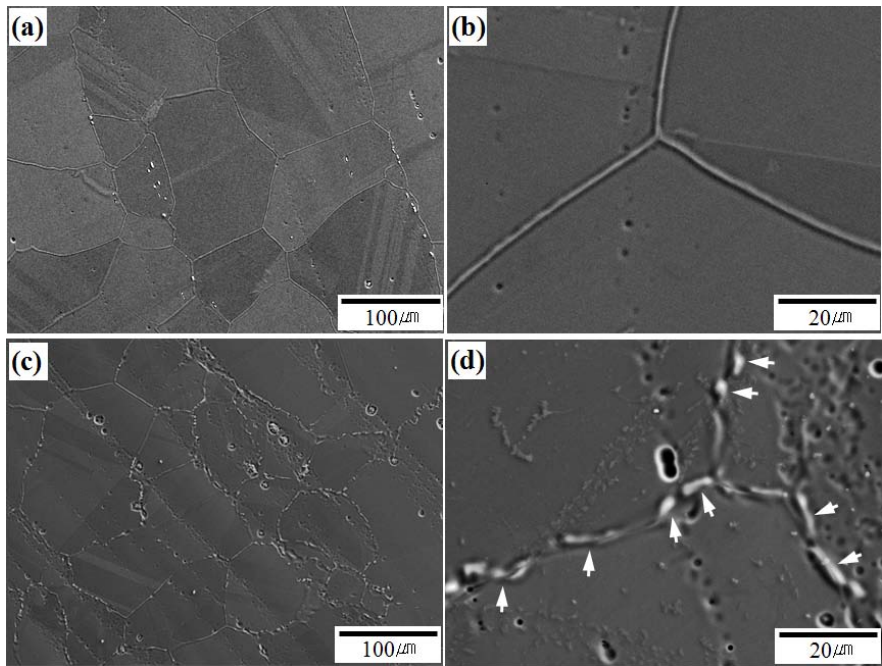

Figure 6. Comparison of liquated GBs between unserrated and serrated specimens simulated at $1180^{\circ} \mathrm{C}$ : (a), (b) for the userrated sample and (c), (d) for the serrated sample. The arrows indicate the liquid pocket in Figure 6d. 
On the mechanism of the formation of serrated GBs

The onset of GB serration at the early stage of slow cooling process is crucial for the development of an understanding of the mechanism for the formation of serrated GBs. An EELS study was conducted on serrated GBs just before $\mathrm{M}_{23} \mathrm{C}_{6}$ precipitation. To exclude the influence of GB characteristics on the serration behavior, only random or high-angle GBs $(\Sigma>29)$ were selected. As shown in Figures 7a-7c, both carbon (C-K edge) and chromium (Cr- $\mathrm{L}_{2}$ edge) atoms segregated discontinuously at the curved regions of the serrated GB. No other atoms such as Co, Mo, $\mathrm{W}, \mathrm{Ti}$ were detectable within the limitation of the EELS system. The formation of Cr-rich carbides did not occur at the segregated region. On the contrary, the straight GB of standard heat-treated specimen shows the continuous segregation of both $\mathrm{C}$ and $\mathrm{Cr}$ atoms along GB (Figures 7d-7f). The discontinuous GB segregation of $\mathrm{C}$ and $\mathrm{Cr}$ atoms may lead to the lattice distortional strain differences along GB while the continuous segregation may lead to a balanced strain. In the segregated region, excess $C$ and $\mathrm{Cr}$ atoms will generate the lattice distortional strain energy near GBs. McLean [19] proposed the following equation for the lattice distortion energy, $W$, generated by a solute atom in the bulk by using elastic continuum theory:

$W=24 \pi K \mu r_{0}\left(r_{1}-r_{0}\right)^{2} /\left[3 K+4 \mu\left(r_{0} / r_{1}\right)\right]$ (2)

where, $K$ is the bulk modulus of the solute, $\mu$ the shear modulus of the solvent, and $r_{0}$ and $r_{1}$ the radius of solvent and solute atoms, respectively. Accordingly, the strain energies due to $\mathrm{C}$ and $\mathrm{Cr}$ segregation are estimated to be $47.9 \mathrm{~kJ} / \mathrm{mol}$ and $1.2 \mathrm{~kJ} / \mathrm{mol}$, respectively when the assumption is made that carbon atoms are dissolved into octahedral interstitial sites of the nickel solvent and chromium atom into substitutional sites of the nickel solvent. This strain energy will be accumulated near GB and distort the lattice along GB even though the values would be overestimated due to relatively open structures of GBs. When the strain differences along GB occur due to discontinuous segregation, it is probable that the local segments of GB would be placed in a pushed or pulled condition to relieve the uneven distortional lattice strain. On the other hand, the local segments of GB may be placed in a balanced condition if the even strain along GB is developed due to continuous segregation. Winning et al. [22] demonstrated that high angle GBs can be moved by an external shear stress which exerts a force on the dislocations in GBs retaining a strain field. With a similar sense, the current understanding is that a stress due to the uneven distortional lattice strain may develop near GBs, and trigger the onset of GB serration. It is worth mentioning that the economy achieved by mitigating unbalanced strain energy along GB seems to be insufficient to provide a driving force for the formation of serrated GB in view of the increase in GB surface. As previously inferred, the fundamental driving force for the GB serration stems in part from lowering interfacial free energy of GB per unit area. Hence, the GB serration involves problems of kinetics rather than mere equilibrium considerations since it also reflects crystal shapes with a consideration of free energies [23].

This GB serration in a nickel-based superalloy Alloy 263 containing a $\gamma^{\prime}$ volume fraction below $10 \%$ appears to be analogous in many ways to the faceting mechanism. It has been reported that GBs are frequently faceted in various materials in order to have lower energy interfaces since certain GB inclinations are energetically preferred over others [23-26]. Most remarkably, Hsieh and Balluffi [25] have made a direct observation of roughening/de-faceting phase transition in GBs, which is shown to be reversible. Of special interest in their work is the result that the straight GB at high temperature tended to adopt quickly a characteristic configuration at each temperature during cooling, and sharply faceted boundaries were recovered at room temperature without any interactions of GB second phase particles. Furthermore, Donald [26] demonstrated that the onset of faceting is often brought on by the addition of certain chemical elements.

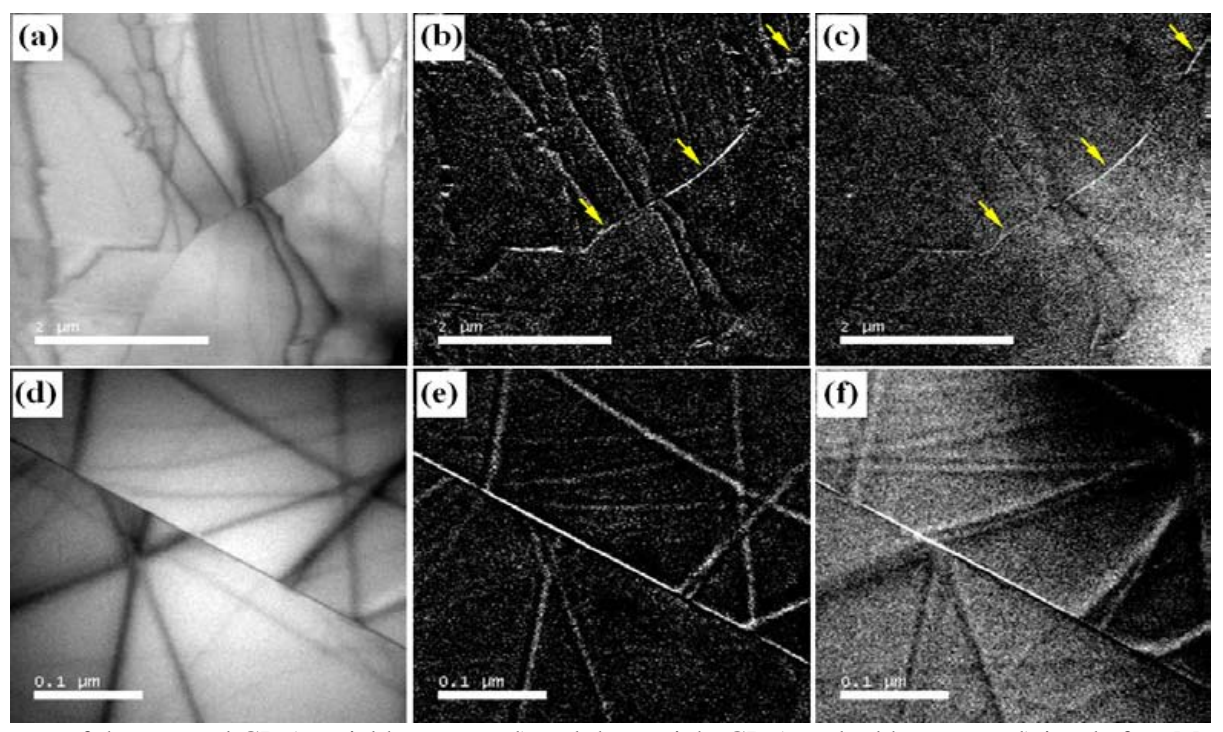

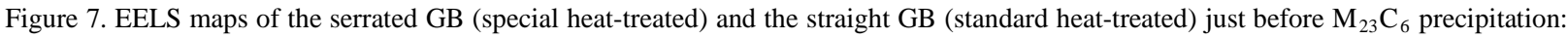
TEM micrograph of (a) serrated GB and the corresponding EELS map of (b) carbon and (c) chromium, and TEM micrograph of (d) straight GB and the corresponding EELS map of (e) carbon and (f) chromium. Noticeable segregation regions are indicated by arrows. 
In order to make it clear that the onset of GB serration can be promoted by the distortional lattice stresses exerting on GBs, large size $\mathrm{Zr}$ atom segregation to GBs was employed based on the McLean's lattice distortion theory [19]. The strain energy due to $\mathrm{Zr}$ segregation is estimated to be as high as $120.5 \mathrm{~kJ} / \mathrm{mol}$. Nibased binary model alloys (Ni-(0.012 0.3)Zr, Ni-0.6C) were prepared with about $100 \mu \mathrm{m}$ grain size. The alloy concept was designed to have serrated GBs without any GB $2^{\text {nd }}$ phase particles or primary $\gamma^{\prime}$. According to phase diagram and thermodynamic calculations of the Ni-Zr alloy system, the $(\mathrm{Ni}, \mathrm{Zr})$ precipitates begin to form during solution treatment when $\mathrm{Zr}$ content is higher than 2.7 wt.\%. Both $\mathrm{Zr}$ and $\mathrm{C}$ contents in each ingot were measured by inductively coupled plasma atomic emission spectroscopy (ICP-AES) method. The model alloys were specially heat-treated to study whether the formation of serrated GBs occurred or not.

Figure 8 shows the serrated GB fraction in Ni-xZr (x: 0.012 0.3) binary model alloy with different $\mathrm{Zr}$ content. The serrated GBs were defined as GBs with their amplitude larger than $0.5 \mu \mathrm{m}$ in the present study. It is clear that the formation of serrated GBs begins to occur when large size $\mathrm{Zr}$ content is higher than $0.05 \%$, which might lead to a sufficient development of stress exerting a force on GBs. Further study is needed to estimate the critical value of stress necessary for the onset of GB serration. The specimen with the lower amount of $\mathrm{Zr}$ shows no serrated GBs (serrated GB fraction less than 1\%). The fraction of serrated GBs with $\mathrm{Ni}_{\mathrm{x}} \mathrm{Zr}_{\mathrm{y}}$ precipitates increases with increasing $\mathrm{Zr}$ content in the range of $0.05 \sim 0.3$ wt.\%.

Figure 9 shows the corresponding microstructures. Ni-0.012Zr alloy shows no serrated GBs (Figure 9a), and high amount of $\mathrm{Zr}$ (Ni-0.3Zr alloy) causes the formation of (Ni,Zr) precipitates after GB serration (Figure 9c). Figure 9b is worth noting that serrated GBs were formed without GB $2^{\text {nd }}$ phase particles. Furthermore, the formation of serrated GBs can be controlled by the addition of large size atoms which might lead to a sufficient development of stress exerting a force on GB.

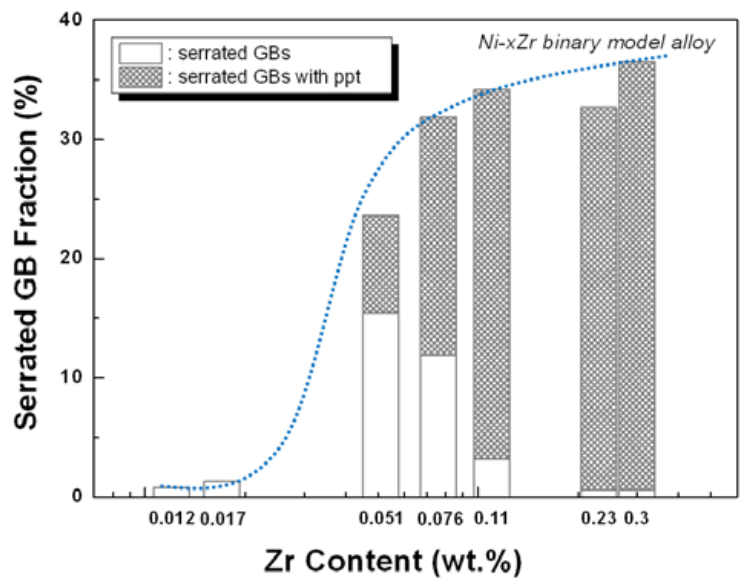

Figure 8. Comparison of serrated GB fractions with different $\mathrm{Zr}$ content in Ni-Zr binary model alloy.

On the other hand, there is no serrated GB in Ni-0.6C model alloy (Figure 9d). It might be inferred that even high amount of carbon atoms do not develop lattice distortional strain near GBs high enough to cause the onset of GB serration because GBs appear to accommodate small interstitial carbon atoms well. However, if $\mathrm{Cr}$ atoms are present in the alloy, $\mathrm{Cr}$ might segregate to GB due to its strong affinity with $\mathrm{C}$ so that high lattice distortional strain near GB is likely to be produced. Thus, the consideration, which is associated with a sufficient development of stress exerting a force on GB to trigger the onset of GB serration, may include an interaction between solute atoms as well as atomic size difference and diffusivity of solute atoms.
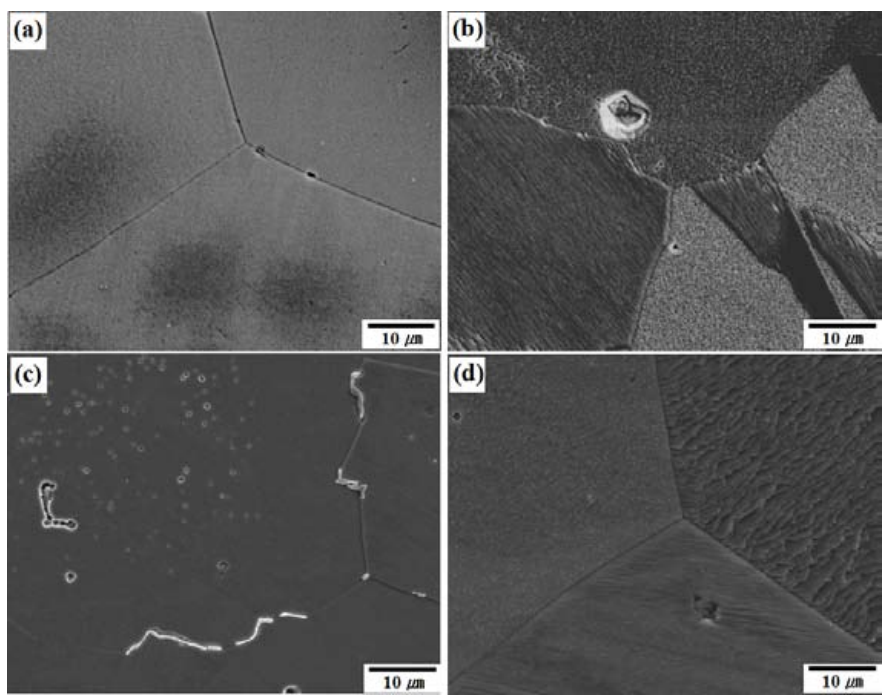

Figure 9. SEM micrographs showing GB configurations: (a) Ni-0.012Zr, (b) Ni-0.051Zr, (c) Ni-0.3Zr and (d) Ni-0.6C. 


\section{Conclusions}

It was found that GB serration occurs prior to the formation of $\mathrm{M}_{23} \mathrm{C}_{6}$ or without interaction of $\gamma^{\prime}$ particles in a wrought Ni-based superalloy Alloy 263 containing $\gamma^{\prime}$ volume fraction below $10 \%$. The serration leads to a change in GB character as a special boundary as well as the carbide characteristics. The fundamental driving force for the GB serration stems in part from lowering interfacial free energy of GB per unit area. Further study on the mechanism of the serration is in progress, however, the current understanding is that the high lattice distortional strain near GBs due to discontinuous solute segregation may promote the onset of GB serration.

\section{Acknowledgement}

The authors acknowledge the financial support of MKE (Ministry of Knowledge Economy), Account No. UCN283-2881.C, which made this work possible.

\section{References}

1. J.M. Larson and S. Floreen, "Metallurgical Factors Affecting the Crack Growth Resistance of a Superalloy”, Metall. Trans. A, 8 (1977), 51-55.

2. A.K. Koul and G.H. Gessinger, "On the Mechanism of Serrated Grain Boundary Formation in Ni-Based Superalloys", Acta Metall., 31 (1983), 1061-1069.

3. H. Loyer Danflou, M. Marty and A. Walder, "Formation of Serrated Grain Boundaries and Their Effect on the Mechanical Properties in a P/M Nickel Base Superalloy”, Superalloys 1992, Edited by S.D. Antolovich, R.W. Stusrud, R.A. MacKay, D.L. Anton, T. Khan, R.D. Kissinger and D.L. Klarstrom, TMS Warrendale PA, 1992, 63-72.

4. M.F. Henry, Y.S. Yoo, D.Y. Yoon and J. Choi, “The Dendritic Growth of $\gamma^{\prime}$ Precipitates and Grain Boundary Serration in a Model Nickel-Base Superalloy”, Metall. Trans. A, 24 (1993), 1733-1743.

5. R.J. Mitchell, H.Y. Li and Z.W. Huang, "On the Formation of Serrated Grain Boundaries and Fan Type Structures in an Advanced Polycrystalline Nickel-Base Superalloy”, J. Mater. Process Technol., 209 (2009), 1011-1017.

6. A.K. Koul and R. Thamburaj, "Serrated Grain Boundary Formation Potential of Ni-Based Superalloys and Its Implications”, Metall. Trans. A, 16 (1985), 17-26.

7. H.U. Hong, I.S. Kim, B.G. Choi, M.Y. Kim and C.Y. Jo, "The Effect of Grain Boundary Serration on Creep Resistance in a Wrought Nickel-Based Superalloy”, Mater. Sci. Eng. A, 517 (2009), 125-131.

8. H.U. Hong, I.S. Kim, B.G. Choi, Y.S. Yoo and C.Y. Jo, "On the Role of Grain Boundary Serration in Simulated Weld HeatAffected Zone Liquation of a Wrought Nickel-Based Superalloy”, Metall. Mater. Trans. A, 43 (2012), 173-181.
9. J.C. Zhao, V. Ravikumar and A.M. Beltran, "Phase Precipitation and Phase Stability in Nimonic 263”, Metall. Mater. Trans. A, 32 (2001), 1271-1282.

10. H.U. Hong, I.S. Kim, B.G. Choi, C.Y. Jo, Y.S. Yoo, H.W. Jeong and S.M. Seo, "Method of Heat treatment of Ni Based Superalloy for Wave Type Grain-Boundary and $\mathrm{Ni}$ Based Superalloy the Same”, 2009, US Patent Application Serial No. $12 / 484,597$

11. H.U. Hong and S.W. Nam, "Crystallographic Investigations on the Serrated Grain Boundaries in an AISI 316 Stainless Steel”, Z. Metallkd., 92 (2001), 1331-1334.

12. H.W. Jeong, S.M. Seo, H.U. Hong and Y.S. Yoo, "Characterization of the Parameters relating Adjacent Grains using Transmission Electron Microscopy”, J. Appl. Cryst., 43 (2010), 1495-1501.

13. H.U. Hong, H.W. Jeong, I.S. Kim, B.G. Choi, Y.S. Yoo and C.Y. Jo, "Significant Decrease in Interfacial Energy of Grain Boundary through Serrated Grain Boundary Transition", submitted to Phil. Mag. (2011).

14. H.U. Hong, B.S. Rho and S.W. Nam, "Correlation of the $\mathrm{M}_{23} \mathrm{C}_{6}$ Precipitation Morphology with Grain Boundary Characteristics in Austenitic Stainless Steel”, Mater. Sci. Eng. A, 318 (2001), 285-292.

15. G.S. Rohrer, V. Randle, C.S. Kim and Y. Hu, "Changes in the Five-Parameter Grain Boundary Character Distribution in $\alpha$-Brass brought about by Iterative Thermomechanical Processing”, Acta Mater., 54 (2006), 4489-4502.

16. H. Guo, M.C. Chaturvedi, N.L. Richards and G.S. McMahon, "Interdependence of Character of Grain Boundaries, Intergranular Segregation of Boron and Grain Boundary Liquation in Simulated Weld Heat-Affected Zone in Inconel 718”, Scripta Mater., 40 (1999), 383-388.

17. W. Chen, M.C. Chaturvedi and N.L. Richards, "Effect of Boron Segregation at Grain Boundaries on Heat-Affected Zone Cracking in Wrought Inconel 718”, Metall. Mater. Trans. A, 32 (2001), 931-939.

18. L. Karlsson and H. Nordén, "Non-Equilibrium Grain Boundary Segregation of Boron in Austenitic Stainless Steel-II. Fine Scale Segregation Behaviour, Acta Metall., 36 (1988), 13-24.

19. D. McLean, Grain Boundaries in Metals, Oxford University Press, London, 1957.

20. C.S. Smith, "Grains, Phases, and Interfaces: An Interpretation of Microstructure”, Trans. AIME, 175 (1948), 15-51.

21. O.A. Ojo and M.C. Chaturvedi, "Liquation Microfissuring in the Weld Heat-Affected Zone of an Overaged PrecipitationHardened Nickel-Base Superalloy”, Metall. Mater. Trans. A, 38 (2007), 356-369.

22. M. Winning, G. Gottstein and L.S. Shvindlerman, "Migration of Grain Boundaries under the Influence of an External Shear Stress”, Mater. Sci. Eng. A, 317 (2001), 17-20. 
23. C. Herring, "Some Theorems on the Free energies of Crystal Surfaces”, Phys. Rev., 82 (1951), 87-93.

24. J.W. Cahn, "Transitions and Phase Equilibria among Grain Boundary Structure”, J. Physique, 43(Colloq. 6, Suppl. 12) (1982), 199-213.
25. T.E. Hsieh and R.W. Balluffi, "Observation of Roughening/De-Faceting Phase Transitions in Grain Boundaries", Acta Metall., 37 (1989), 2133-2139.

26. A. Donald, "Some Observations on Grain Boundaries in Copper-Bismuth Alloys”, Phil. Mag., 34 (1976), 1185-1189. 